Review Article

\title{
Gut Microbiota as a Prospective Therapeutic Target for Curcumin: A Review of Mutual Influence
}

\author{
Wissam Zam (ic) \\ Department of Analytical and Food Chemistry, Faculty of Pharmacy, Al-Andalus University for Medical Sciences, Tartous, Syria \\ Correspondence should be addressed to Wissam Zam; ws.sarah2005@gmail.com
}

Received 8 October 2018; Revised 6 November 2018; Accepted 27 November 2018; Published 16 December 2018

Guest Editor: Jinkai Zheng

Copyright (c) 2018 Wissam Zam. This is an open access article distributed under the Creative Commons Attribution License, which permits unrestricted use, distribution, and reproduction in any medium, provided the original work is properly cited.

\begin{abstract}
Background. Turmeric is a spice that has recently received much interest and has been widely used in Ayurvedic medicine. Turmeric products are diarylheptanoids and have been characterized as safe. They are termed as curcuminoids that consists essentially of three major compounds: curcumin, demethoxycurcumin, and bisdemethoxycurcumin. Curcumin is a lipophilic polyphenol that has poor systemic bioavailability and suffers from biotransformation by human intestinal microflora to yield different metabolites that are easily conjugated to glucuronides and sulfate $\mathrm{O}$-conjugated derivatives. Recently, an increasing number of studies have indicated that dysbiosis is linked with many metabolic diseases, though gut microbiota could be a novel potential therapeutic target. Scope and Approach. Thus, it is suspected that curcumin and its derivatives exert direct regulative effects on the gut microbiota which could explain the paradox between curcumin's poor systemic bioavailability and its widely reported pharmacological activities. Key Findings and Conclusions. This article summarizes a range of studies that highlight the interaction between curcumin and gut microbiota and considers opportunities for microbiome-targeting therapies using turmeric extract.
\end{abstract}

\section{Introduction}

Curcuma longa (turmeric) and more specifically curcumin, the main constituent of turmeric, are receiving increased clinical attention globally due to raising evidences on their therapeutic potential effects [1]. It has been demonstrated that curcumin and the whole turmeric rhizome has some potential effects in the context of chronic disease such as gastrointestinal and neurological disorders, diabetes, and cancer [2-4]. These health effects may be promoted despite low absorption by modulating intestinal barrier function [5]. Such barrier effects will in turn promote changes in the composition and diversity of the gut microbiota [5].

This article summarizes a range of studies that highlight the interaction between curcumin and gut microbiota and considers opportunities for microbiome-targeting therapies using turmeric extract.

\section{Curcumin}

Curcumin is the product obtained by solvent extraction of turmeric and purification of the extract by crystallization. Turmeric is a spice cultivated in India and other parts of Southeast Asia and used in curries and mustards. It is a rhizomatous herbaceous perennial plant (Curcuma longa) of the ginger family (Zingiberaceae) that has received much interest from the culinary world as well as from the medical and scientific worlds [6, 7]. Turmeric products have been characterized as safe by several committees including the Food and Drug Administration (FDA) in the USA, the Joint Expert Committee of the Food and Agriculture Organization/World Health Organization (FAO/WHO), the Natural Health Products Directorate of Canada, and the Codex Alimentarius [8, 9]. Major phytoconstituents of turmeric are diarylheptanoids, which occur in a mixture termed curcuminoids that consists of two methoxylated phenols connected by two $\alpha, \beta$ unsaturated carbonyl groups that exist in a stable enol form, and they generally make up approximately $1-6 \%$ of turmeric by dry weight $[10,11]$. The product consists essentially of three major compounds (Figure 1): curcumin (1,7-bis(4-hydroxy3-methoxyphenyl)-1,6-heptadiene-3,5-dione, typically $60-70 \%$ of a crude extract), demethoxycurcumin 


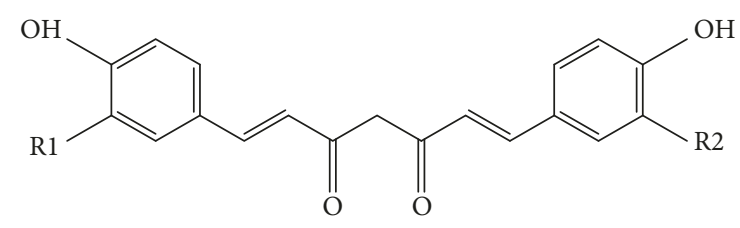

(1) $\mathrm{R} 1=\mathrm{R} 2=\mathrm{OCH} 3$

(2) $\mathrm{R} 1=\mathrm{OCH} 3, \mathrm{R} 2=\mathrm{H}$

(3) $\mathrm{R} 1=\mathrm{R} 2=\mathrm{H}$

FIGURE 1: Structures of (1) curcumin (diferuloylmethane), (2) demethoxycurcumin, and (3) bisdemethoxycurcumin.

(1-(4-hydroxyphenyl)-7-(4-hydroxy-3-methoxyphenyl)hepta-1,6-diene-3,5-dione, 20-27\%), and bisdemethoxycurcumin (1,7-bis-(4-hydroxyphenyl)-hepta-1,6-diene-3, 5-dione, 10-15\%) [6]. Curcuminoids are also reported from more than 120 Curcuma plants such as C. phaeocaulis, C. aromatica, C. xanthorrhiza, C. zedoaria, and C. mangga [12]. Curcumin is a lipophilic polyphenol that is nearly insoluble in water but is readily soluble in organic solvents such as acetone, dimethyl sulfoxide, and ethanol [13]. It is quite stable in the acidic $\mathrm{pH}$ of the stomach [14].

Turmeric is widely employed as a flavoring and coloring agent in food. Besides, it has also been widely used for its pharmacological effects in Ayurvedic medicine including antioxidant [15], analgesic, antiseptic, antispasmodic [16], antimicrobial $[17,18]$, anti-inflammatory $[19,20]$, and anticarcinogenic properties [21]. Curcumin has been consumed as a dietary supplement for centuries and is considered pharmacologically safe based on repeated studies [7]. US FDA added turmeric to the Generally Recognized As Safe (GRAS) list, and an acceptable daily intake level of $0.1-3 \mathrm{mg} / \mathrm{kg}$-BW has been granted to curcumin by the Joint FAO/WHO Expert Committee on Food Additives, 1996 [22]. Lao et al. studied the safety of curcumin in 24 healthy volunteers using curcumin capsules with single escalating doses from $500 \mathrm{mg}$ to $12,000 \mathrm{mg}$. Seven patients developed some first-grade adverse effects, including headaches, rashes, diarrhea, and yellowish stools [23].

Due to its increasing use in dietary supplements, researchers are developing many extraction methods for improving the extraction yield of curcumin. Solvent extraction followed by column chromatography is widely used for the extraction and purification of curcumin. Various methods used for extraction including soxhlet extraction, ultrasonic extraction, zone-refining, microwave, supercritical carbon dioxide, and dipping methodshave been tried [24-28].

The poor bioavailability is still one of the major problems facing the use of curcumin despite its reported benefits [29], which appear to be primarily due to poor absorption, rapid metabolism, and rapid excretion. An oral dose of 1,000 mg/kg of curcumin administered to rat resulted in approximately $75 \%$ of the dose being excreted in feces, and negligible amounts were detected in the urine [30]. Large quantities of curcumin and its metabolites were excreted in the bile of rats after intravenous and intraperitoneal administration, mainly as tetrahydrocurcumin and hexahydrocurcumin glucuronides
[31]. Researchers extended their work to investigate the metabolism of curcumin using suspensions of isolated human liver or gut microsomes, and the results suggested that the metabolic reduction occurred very rapidly within minutes [32].

\section{Gut Microbiota}

All human mucosal surfaces are associated with a diverse microbial community composed mainly of bacteria but also include viruses, fungi, archaea, and protozoa [33]. The exceptionally complicated and abundant microbial community inhabits the GI tract, with 100 trillion bacteria which are remarkably 10-100 times more than the quantity of eukaryotic cells [34]. The gut environment differs markedly between different anatomical regions in terms of physiology, substrate availability, digesta flow rates, host secretions, oxygen tension, and $\mathrm{pH}[35,36]$. The large intestine is colonized by the largest obligate anaerobes microbial community due to its slow flow rates and neutral to mildly acidic $\mathrm{pH}[35,36]$. In comparison, the small intestine with its short transit times $(3-5 \mathrm{~h})$ and high bile concentrations provide a more challenging environment for microbial colonizers [35, 36]. Gram-positive streptococci, lactobacilli, and enterococci species and Gram-negative Proteobacteria and Bacteroides are the main facultative anaerobes residing in the jejunum and ileum as revealed by molecular analysis $[35,36]$. Most recently, new technologies were developed, and 900 reference bacterial genome sequences were added by the Human Microbiome Project in order to assess the microbiota composition [37, 38].

The gut microbiota performs a number of essential structural, metabolic, and protective functions for host health as well as a direct action on the gut mucosa, the enteric nervous system, and far beyond the local GI compartment [39-41]. Thus, the gut microbiota resembles an endocrine organ that produces hundreds of products unlike other endocrine systems which secrete a single or at most a small number of humoral agents [42, 43]. This biochemical capacity arises from the vast and diverse array of microbial cells, with an approximate weight of 1 to $2 \mathrm{~kg}$ in an average adult [44].

The disturbance of this complex dual effect between gut microbiota and the host could possibly cause or contribute to disease. Accordingly, researchers are greatly interested in the diagnostic of alterations in the microbial ecology of the gut which could open new approaches in preventing or treating disease through the manipulation of the microbial gut community.

\subsection{Dysbiosis of the Gut Microbiota in Disease}

3.1.1. Gut Dysbiosis. The alteration in the composition of the gut microbiota is known as gut dysbiosis and can result from exposure to various environmental factors, including diet, drugs specially antibiotics, toxins, pathogens, and increased stress [45].

The alteration in microbiota may explain why some individuals have greater risk to develop certain diseases [46]. 
Studies using germ-free mouse models gave the strongest evidence of the direct involvement for the gut microbiota in disease pathogenesis and it was proved that under germ-free conditions, the incidence and the severity of disease is reduced consistent with the microbiota being a "trigger" for disease progression [46].

Various homeostatic functions of the human body could be distributed due to gut dysbiosis and this is increasingly linked to several non-communicable diseases including infectious diseases, diabetes [47], obesity [48], cancer [49], allergic asthma [50], autoimmune diseases [51], and others as presented in Figure 2.

Several studies have demonstrated an important relationship between infection and dysbiosis [52] such as the infection with Clostridium difficile [53] and Helicobacter pylori [54]. Results also showed that infection is associated not only with the microbiome, but also with viruses [55] such as human immunodeficiency virus (HIV) [56] and hepatitis B virus (HBV) [57].

An increasing number of studies have indicated a great interaction between the gut microbiota dysbiosis and several metabolic disorders including obesity and diabetes $[58,59]$. Germ-free mice have reduced adiposity and improved tolerance to glucose and insulin when compared with conventional counterparts when fed a Western-style diet [60]. Increased adiposity was observed in lean mice after receiving a microbiota transplant from genetically obese mice characterized by an altered microbiota [61]. These interactions are mediated via several mechanisms including the potential to increase nutrient harvest and energy extraction from food; and alter appetite signaling and the immune response $[62,63]$.

The relationship between human carcinogenesis and specific pathogenic bacteria has been widely investigated. Multiple studies revealed that individuals diagnosed with gastrointestinal malignancy have different gut microbiome composition compared with healthy individuals. The chronic inflammation caused by Helicobacter pylori is considered to be the strongest risk factor for gastric cancer and its eradication before the onset of chronic atrophic gastritis may protect against gastric cancer [63]. Beyond $H$. pylori, the synergetic colonization of altered Schaedler's flora causes gastric corpus inflammation, epithelial hyperplasia, and dysplasia in insulin-gastrin mice [64]. The effect of the gut microbiome in the development and progress of colorectal cancer has recently become a major focus of research. An increase in adenomas or colorectal cancer is observed in subjects with a high proportion of potential pathogens, such as Helicobacter, Pseudomonas, and Acinetobacter, and a lower richness of beneficial bacteria especially butyrate-producing bacteria [65]. A significant increase in Bacteroides massiliensis, Bacteroides vulgatus, Bacteroides ovatus, Fusobacterium nucleatum, and E. coli has also been observed from advanced adenoma to carcinoma [66, 67]. Sharma et al. showed an association between Salmonella and gallbladder cancer [68]. Cancer risk is also influenced by viruses which are also a component of the gut microbiome. For example, DNA from human papillomavirus (HPV) is detected in almost all cervical cancers [69].
On the contrary, accumulating evidence indicates that the therapeutic activity and the side effects of anticancer agents administered orally or parenterally could both be influenced by the gut microbiota via pharmacodynamics and immunological mechanisms [70].

Several gut microbiota mechanisms are involved in the promotion of autoimmunity. It is hypothesized that an aberrant modification of host proteins could be due to the changed spectrum of microbial enzymes involved in posttranslational modification of proteins (PTMP) which may contribute to autoimmune diseases by generating autoimmune responses [71]. Under the germ-free conditions, no autoimmune disease is developing in the animal models, while some bacterial species are directly linked to the progression of specific autoimmune diseases [72]. Reduction of Firmicutes and Bacteroides and the overgrowth of Proteobacteria are linked to inflammatory bowel disease [72]. Increasement in Porphyromonas, Prevotella, and Leptotricha species could trigger rheumatoid arthritis [73]. Decreased Clostridia clusters XIVa and IV and Bacteroidetes are linked to multiple scelorsis [74].

\subsection{Life Style and Dietary Effect on Gut Microbiota.} Smoking, stress, and lack of exercise can greatly impact the gut microbiota composition. Indeed, smoking has a great impact on gut microbiota composition by increasing Bacteroides-Prevotella [75]. Stress has a significant influence on colonic motor activity via the gut-brain axis involving both hormonal and neuronal pathways. This impact is associated with an altered gut microbiota profiles, including a decrease in numbers of potentially beneficial Lactobacillus [41, 76].

Protein, carbohydrates, and fat are the most comment and major components in diets of human that have been widely found to impact the composition of the gut microbiota in the host. The end products of protein degradation at the distal end of the colon are amino acids, amines, ammonia, and SCFA. A diet containing a high concentration of cysteine or threonine can cause a significant increase in beneficial microbiota such as lactobacilli or bifidobacteria and a decrease in Clostridiaceae [77]. Complex carbohydrates such as insulin and oligosaccharides, also referred to as prebiotics, can be degraded by proteolytic enzymes into short chain fatty acids and various gases and are normally an important energy resource for microbial growth. Prebiotics also act as important stimulants which promote the growth of beneficial bacteria such as bifidobacteria and lactobacilli [78]. The consumption of high-fat foods tends to induce substantial alterations in the composition of GI tract microbiota by increasing Rikenellaceae and decreasing Ruminococcaceae [79].

Habitual dietary pattern and shorter term dietary variation influences gut microbiota composition at the genus and species level. Western diet characterized by a high proportion of total and saturated fats, animal protein, and simple sugars with a low proportion of plant-based foods, is associated with gut microbial populations that are typified by a Bacteroides enterotype. In contrast, plant based 


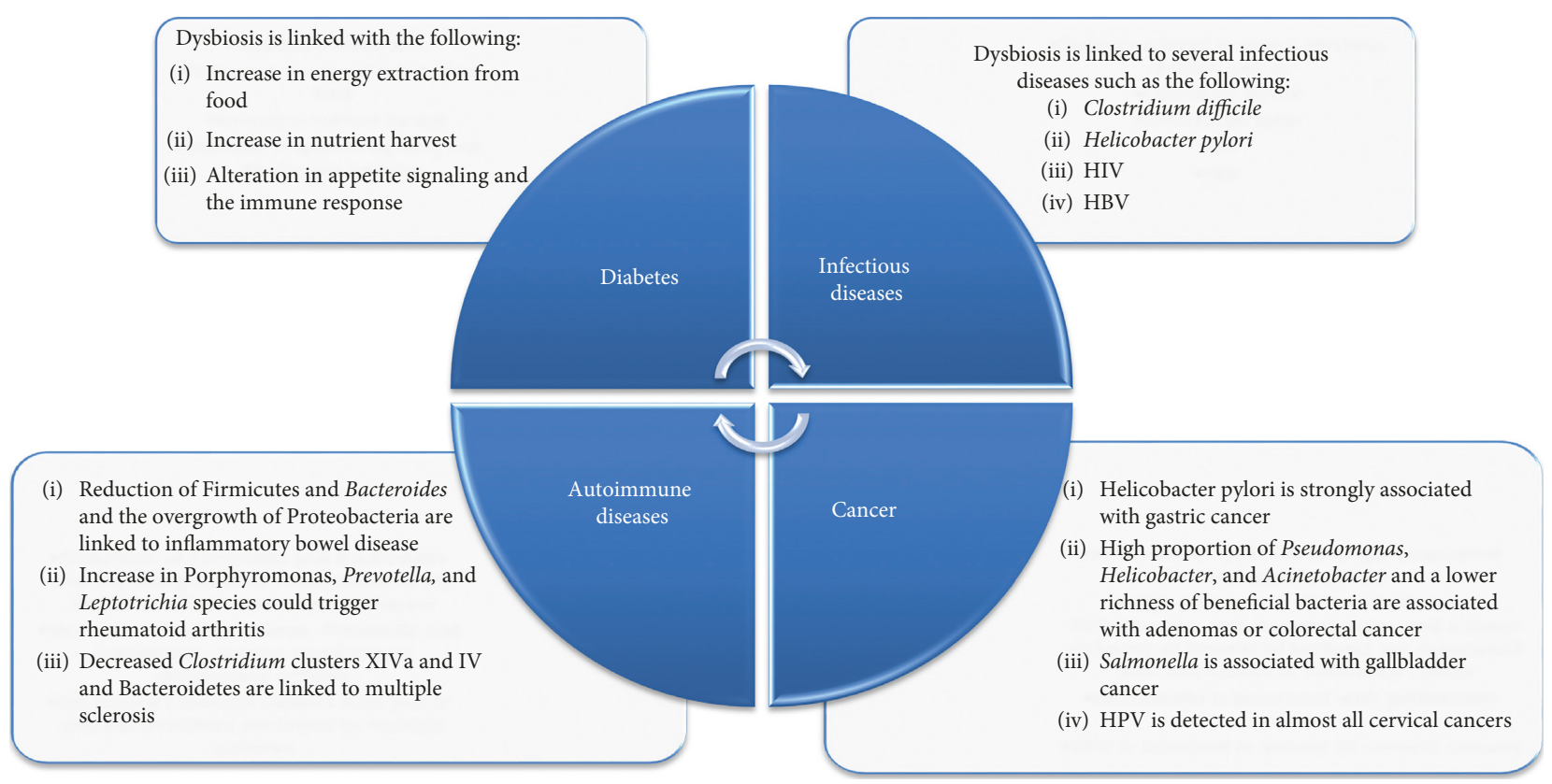

Figure 2: The impact of gut dysbiosis on diseases.

diets containing a high proportion of polysaccharides are associated with a Prevotella enterotype known to use cellulose and xylans as substrates $[80,81]$ with a greater diversity of the fecal microbiota compared with individuals consuming habitual Western diets [82].

Rapid and marked alterations in fecal microbiota composition especially in Bacteroides to Prevotella ratio are observed when replacing a habitual Western diet with one high in fiber can cause [80]. The Mediterranean diet based on fruits and vegetables, monounsaturated and polyunsaturated fats and grains, is considered as a standard diet for a healthy life style. Individuals fed on the Mediterranean diet have lower numbers of Bacillaceae and Proteobacteria but higher Clostridium and Bacteroidetes populations [83]. Additionally, vegetarian diets could decrease the ratio of Clostridium cluster XIVa species, but increase the number of Faecalibacterium prausnitzii, Clostridium clostridioforme, and Bacteroides Prevotella [84].

\section{Effects of Curcumin on Gut Microbiota}

Aside of the poor systemic bioavailability of curcumin, it is expected to find it at high concentrations in the gastrointestinal tract after oral administration. Thus, it is suspected that curcumin could exert direct regulative effects on the gut microbiota which could explain the paradox between curcumin's poor systemic bioavailability and its widely reported pharmacological effects, as resumed in Table 1 [85]. The administration of curcumin significantly shifted the ratio between beneficial and pathogenic microbiota by increasing the abundance of bifidobacteria, lactobacilli, and butyrateproducing bacteria and reducing the loads of Prevotellaceae, Coriobacterales, enterobacteria, and enterococci. These alterations in gut microbiota could explain the immune modulation and antihyperlipidemia efficacy of curcumin aside of its anti-inflammatory and anticolonotropic carcinogenicity activity.

Shen et al. [86] investigated the regulative effects of oral curcumin administration of $100 \mathrm{mg} / \mathrm{kg}$ body weight on the gut microbiota of C57BL/6 mice. After 15 days of continuous once daily oral dose of curcumin, a total of 370 shared operational taxonomic units (OTUs) between the curcumin and control groups, and 39 were unique in the curcumin group and 79 in the control group. Curcumin was found to decrease the microbial richness and diversity, with significant differences in abundance between the curcumin and control groups in three bacterial families [86]. A significant decrease in the abundance of Prevotellaceae was observed, while the abundance of Bacteroidaceae and Rikenellaceae was significantly increased in the curcumin group [86]. Prevotella species are anaerobic Gram-negative bacteria of the Bacteroidetes phylum that were found to be greater in CRC patients than in stool from cancer-free patients [87]. The role of Prevotella in driving Th17-mediated immune responses in periodontitis is clarified by results of studies that found a significant link between IL-1a and IL-1b levels in crevicular fluid and Prevotella colonization [88].

In order to study the effect of curcumin-supplemented diet on colonotropic carcinogenicity, mice received intraperitoneal injections of the mutagenic agent azoxymethane. A relative increase in the abundance of Lactobacillales and a decrease in Coriobacterales order was observed with a curcuminsupplemented, and this effect was correlated with entire eliminated tumor burden [89]. A large systemic review summarizes the original articles studying the relation between microbiota and colorectal cancer until November 2014. It showed that some bacteria are consistently diminished in colorectal cancer such as Bifidobacterium, Lactobacillus, Ruminococcus, and Faecalibacterium spp, while others are 
TABLE 1: Effects of curcumin on gut microbiota.

\begin{tabular}{|c|c|c|c|}
\hline Dose & Effect on microbiota & Benefits and mechanism & References \\
\hline $\begin{array}{l}100 \mathrm{mg} / \mathrm{kg} \text { once } \\
\text { daily for } 15 \text { days }\end{array}$ & $\begin{array}{l}\text { A significant decrease in the abundance of } \\
\text { Prevotellaceae was observed, while the } \\
\text { abundance of Bacteroidaceae and } \\
\text { Rikenellaceae was significantly }\end{array}$ & $\begin{array}{l}\text { Prevotella species were found to be greater in CRC } \\
\text { patients. The role of Prevotella in driving Th17- } \\
\text { mediated immune responses is clarified by the } \\
\text { increase of IL-1a and IL-1b levels in crevicular fluids }\end{array}$ & {$[86-88]$} \\
\hline $\begin{array}{l}\text { Curcumin- } \\
\text { supplemented } \\
\text { diet at doses up to } \\
8000 \text { mg per day }\end{array}$ & $\begin{array}{l}\text { A relative increase in the abundance of } \\
\text { Lactobacillales and a decrease in } \\
\text { Coriobacterales order was observed }\end{array}$ & $\begin{array}{c}\text { Curcumin possesses anticancer activity in vitro and in } \\
\text { preclinical animal models via the activation of } \\
\text { caspases } 9,3 \text {, and } 8 \text { in the colon cancer cell lines. } \\
\text { It also inhibited the proliferation and induced } \\
\text { apoptosis through the COX-2 and non-COX-2 } \\
\text { pathways. } \\
\text { It has also the potential to target cancer stem cells } \\
\text { (CSC) through direct or indirect influences on the } \\
\text { CSC self-renewal pathways. }\end{array}$ & [89-96] \\
\hline $\begin{array}{l}0.2 \%(\mathrm{w} / \mathrm{w}) \\
\text { nanoparticles } \\
\text { of curcumin }\end{array}$ & $\begin{array}{l}\text { An increase in the abundance of butyrate- } \\
\text { producing bacteria and fecal butyrate level } \\
\text { was observed }\end{array}$ & $\begin{array}{l}\text { Nanoparticles of curcumin suppressed mucosal } \\
\text { mRNA expression of inflammatory mediators and the } \\
\text { activation of NF- } \kappa \text { B in colonic epithelial cells }\end{array}$ & [97] \\
\hline $\begin{array}{l}\text { Up to } \\
2000 \mathrm{mg} / \text { day }\end{array}$ & $\begin{array}{l}\text { Curcumin-supplementation showed fewer } \\
\text { proinflammatory enterobacteria and } \\
\text { enterococci and higher anti-inflammatory } \\
\text { bifidobacteria and lactobacilli loads }\end{array}$ & $\begin{array}{c}\text { It can ameliorate intestinal inflammation through } \\
\text { modulation of intracellular signaling transduction } \\
\text { pathways and different molecular pathways including } \\
\text { immunoregulatory and anti-inflammatory } \\
\text { mechanisms }\end{array}$ & {$[98-101,105]$} \\
\hline $\begin{array}{l}\text { Low dose of } \\
\text { curcumin }(1 \mathrm{~g} / \text { day })\end{array}$ & $\begin{array}{l}\text { An increase in the abundance of butyrate- } \\
\text { producing bacteria }\end{array}$ & $\begin{array}{c}\text { Antiatherogenic and antihypercholesterolemia effects } \\
\text { by increasing HDL levels }\end{array}$ & {$[102,106,107]$} \\
\hline $\begin{array}{l}\text { Low dose of } \\
\text { curcumin }(1 \mathrm{~g} / \text { day })\end{array}$ & $\begin{array}{l}\text { Curcumin supplementation shifts the } \\
\text { composition of the gut microbiota toward } \\
\text { that of the lean comparison rats }\end{array}$ & $\begin{array}{c}\text { Curcumin attenuates Western diet-induced } \\
\text { development of type } 2 \text { diabetes mellitus and } \\
\text { atherosclerosis }\end{array}$ & {$[103,104]$} \\
\hline $100 \mathrm{mg} / \mathrm{kg} /$ day & $\begin{array}{l}\text { Curcumin could partially reverse changes in } \\
\text { the diversity of gut microbiota in estrogen } \\
\text { deficient rats. } \\
\text { At the phyla level, a decrease of phyla } \\
\text { Firmicutes and Bacteroidetes was observed. }\end{array}$ & $\begin{array}{l}\text { Curcumin had a significant preventive effect on body } \\
\text { weight gain. In addition, it decreases the estradiol } \\
\text { serum levels. }\end{array}$ & [108] \\
\hline
\end{tabular}

constantly augmented such as Coriobacteridae. It is also clear that bacteria metabolites amino acids are increased and butyrate is decreased throughout colonic carcinogenesis [90]. Preclinical studies have consistently shown that curcumin possesses anticancer activity in vitro and in preclinical animal models via the activation of caspases 9, 3, and 8 in the colon cancer cell lines SW480 and SW620 [91]. In four colon cancer cell lines (HT-29, IEC-18-k-ras, Caco-2, and SW-480), the use of celecoxib (5lM) and curcumin (10-15lM) inhibited the proliferation and induced apoptosis through the COX-2 and non-COX-2 pathways [92]. Recently, a number of studies have suggested that curcumin has the potential to target cancer stem cells (CSC) through direct or indirect influences on the CSC self-renewal pathways [93]. Its robust activity in colorectal cancer has led to five phase I clinical trials being completed showing the safety and tolerability of curcumin in colorectal cancer patients using doses up to $8000 \mathrm{mg}$ per day $[94,95]$. The success of these trials has led to the development of phase II trials that are currently enrolling patients [96].

In another study, the effects of nanoparticle curcumin on experimental colitis in mice via the modulation of gut microbiota were studied [97]. BALB/c mice were fed with 3\% dextran sulfate sodium in water. Treatment with nanoparticle curcumin suppressed mucosal mRNA expression of inflammatory mediators and the activation of NF- $\kappa \mathrm{B}$ in colonic epithelial cells. These effects were accompanied with an increase in the abundance of butyrate-producing bacteria and fecal butyrate level [97].

Previous studies in active IBD and in experimental DSS-colitis $[98,99]$ have shown that curcumin can ameliorate intestinal inflammation through modulation of intracellular signaling transduction pathways and different molecular pathways including immunoregulatory and antiinflammatory mechanisms $[100,101]$. A preclinical study found an antiatherogenic effect of low dose of curcumin in a mouse model of atherosclerosis [102].

It was found that curcumin attenuates Western dietinduced development of type 2 diabetes mellitus and atherosclerosis [103]. This could be explained by the efficacy of curcumin on reversing the effect of high-fat diet on the composition of the gut microbiota by shifting it toward that of the lean comparison rats fed a normal diet [104]. The antiinflammatory effects of curcumin were studied in animal models infected with Toxoplasma gondii. It was found that curcumin-supplemented animals showed fewer proinflammatory enterobacteria and enterococci and higher antiinflammatory bifidobacteria and lactobacilli loads [105]. It was found that low doses of curcumin attenuate dietinduced hypercholesterolemia in rats and boosted highdensity lipoprotein cholesterol levels $[106,107]$.

Estrogen deficiency induced by ovariectomy caused alterations in the structure and distribution of intestinal 
microflora in rats, and the administration of curcumin could partially reverse changes in the diversity of gut microbiota according to Zhang et al. [108]. The effects of curcumin on gut microfloral communities of ovariectomized (OVX) female rats were studied, and the results indicated that gut microbiota of rats from the curcumin-treated group (CUR) had higher levels of biodiversity and unevenness estimations than those from the OVX group [108]. Seven differential gut microbiota (Anaerotruncus, Exiguobacterium, Helicobacter, Papillibacter, Pseudomonas, Serratia, and Shewanella) between OVX and CUR groups were found [108].

Dey et al. transplanted six groups of gnotobiotic mice with fecal microbes derived from one of six healthy adults with various ethnic dietary patterns. The results of this study provided evidence on the impact of regional diets on microbiota function [109]. The authors report that turmeric altered microbiome composition and function, slowed transit by altering bile acid metabolism, and affected intestinal motility [109].

In a more recent study, Peterson et al. investigated the effects of turmeric and curcumin dietary supplementation on human gut microbiota by a double-blind, randomized, placebo-controlled pilot study [110]. Turmeric tablets with extract of piperine (Bioperine), curcumin with Bioperine tablets, or placebo tablets were provided to healthy human subjects and subsequent changes in the gut microbiota were determined by $16 \mathrm{~S}$ rDNA sequencing. The results indicated a significant and individualized variation in gut microbiota over time. Turmeric and curcumin treatment resulted in the reduced average relative abundance of 71 and 56 taxa, respectively [110].

The results of these various studies strongly suggest that curcumin may act as promoting factors of growth, proliferation, or survival for beneficial members of the gut microbiota. A number of mechanisms may account for the stimulatory effect of curcumin. The first proposed mechanism lies on the ability of some microorganisms to use polyphenols as substrates. Besides, phenolic compounds positively affect bacteria consumption of nutrients such as sugars. One study examined the effects of turmeric in 8 healthy human participants fasted for $12 \mathrm{~h}$ and ingested curry and rice with or without turmeric. Results showed that turmeric increased the AUC of breath hydrogen compared with turmeric-free diet, suggesting that dietary turmeric activated carbohydrate colonic fermentation [111].

Another proposed mechanism depends on the increased abundance of certain lactobacilli strains that can strongly inhibit gastrointestinal pathogens due to the production of lactic acid which influences the pathogen invasion of human epithelial cells [112]. Additionally, in the case of some strains, such as L. johnsonii La1 and L. plantarum ACA-DC 287, a combination of lactic acid and bacteriocin-like compounds production was also detected [113].

\section{Effects of Gut Microbiota on Curcumin}

The gut microbiota plays an important role in the metabolism and biotranformation of curcumin into a range of catabolites [29]. It was noticed that the biotransformation of turmeric curcuminoids by human GM is reminiscent of equal production from the soybean isoflavone daidzein [114]. Tan et al. used an in vitro model containing human fecal starters to investigate the colonic metabolism of curcuminoids. Results showed that after $24 \mathrm{~h}$ of fermentation in vitro, up to $24 \%$ of curcumin, $61 \%$ of demethoxycurcumin, and $87 \%$ of bisdemethoxycurcumin were degraded by the human fecal microbiota. Three main metabolites were detected in the fermentation cultures, namely, tetrahydrocurcumin (THC), dihydroferulic acid (DFA), and 1-(4hydroxy-3-methoxyphenyl)-2-propanol [115]. Analyses of microorganisms isolated from human feces revealed that $E$. coli exhibited the highest curcumin-metabolizing activities via NADPH-dependent curcumin/dihydrocurcumin reductase [116].

It has been reported that microbial metabolism of curcumin with Pichia anomala yielded four major metabolites, 5-hydroxy-7-(4-hydroxy-3-methoxyphenyl)1-(4-hydroxyphenyl)heptan-3-one, 5-hydroxy-1,7-bis(4hydroxy-3-methoxyphenyl)heptan-3-one, 5-hydroxy-1, 7-bis(4-hydroxyphenyl)heptane-3-one, 1,7-bis(4-hydroxy-3methoxyphenyl)heptan-3,5-diol, and two minor products [117].

Li et al. proved that the curcumin metabolism in the GI tract is complicated and underwent different stages. They demonstrated that phase I metabolism yielded three metabolites, namely, tetrahydrocurcumin (M1), hexahydrocurcumin (M2), and octahydrocurcumin (M3) [118]. Then, curcumin and these phase I metabolites were subject to conjugation via phase II metabolism to yield their corresponding glucuronide and sulfate $\mathrm{O}$-conjugated metabolites $[119,120]$. Gut microbiota may deconjugate the phase II metabolites and convert them back to the corresponding phase I metabolites and some fission products such as ferulic acid in the cecum and colon [121].

In a recent research, the metabolic profile of curcumin in human intestinal flora was identified in vitro using ultraperformance liquid chromatography/quadrupole time-offlight mass spectrometry. On the basis of the used method and the metabolites identified, reduction, methylation, demethoxylation, hydroxylation, and acetylation were the main pathways by which curcumin was metabolized by human intestinal microflora to yield 23 different metabolites [119]. Reductive metabolites are the predominant metabolites in the human intestinal microflora system and appear to be easily conjugated [120]. Glucuronidation is the dominating pathway of conjugation, and the glucuronide of hexahydrocurcumin is usually found as the major metabolite of curcumin in body fluids, cells, and organs [121].

There is evidence that curcumin metabolites display a similar potency to curcumin [122]. Tetrahydrocurcumin (THC), a major metabolite of curcumin, has been demonstrated to act against neurodegeneration, to prevent inflammation and oxidative stress, and to possess antitumor activity [123]. These effects could be due to the inhibition of prominent cytokines release, including interleukin-6 (IL-6) and tumor necrosis factor- $\alpha$ (TNF- $\alpha$ ); however, octahydrocurcumin $(\mathrm{OHC})$ and hexahydrocurcumin $(\mathrm{HHC}) \mathrm{did}$ not significantly alter cytokine release [123]. Furthermore, 
LPS-mediated upregulation of iNOS and COX-2 as well as $\mathrm{NF}-\kappa \mathrm{B}$ activation were significantly inhibited by the three curcumin metabolites (THC, HHC, and OHC) [124].

A bacterial strain of Bacillus megaterium DCMB-002, isolated from mice feces, showed the capability of transforming curcumin to seven metabolites through different metabolic processes including hydroxylation, demethylation, reduction, and demethoxylation. After $24 \mathrm{~h}$ of incubation, the metabolites exhibited moderate antioxidant activity [125].

\section{Conclusions and Perspective}

Both gut microbiota and diet impact each other and can strongly affect our health. The development of a rich and stable gut microbiota is crucial for maintaining proper host physiologic functions. However, dysbiosis, characterized by reduced diversity and the predominance of a few pathogenic taxa, is linked with many metabolic diseases.

Curcumin attracted researchers and has received worldwide attention for its multiple pharmacological activities, which appear to act primarily through its antiinflammatory and antioxidant mechanisms. Given the low systemic bioavailability of curcumin and its pharmacological therapeutic uses, curcumin might provide benefit by acting on gut microbiota. This impact on the gut microbiota seems to be reasonable and attractable areas of study as no absorption of the parent compound is necessary. In addition, it was proved that the composition of gut microbiota had a profound influence on the biotransformation of curcumin in the colon by various processes mainly by reduction followed by conjugation, which might have a significant impact on the health effects of dietary curcumin, especially in the GI.

Future researches on human volunteers are required to extend the current gut microbiota outcomes in order to provide a basis for gut microbiota-based therapeutic applications of curcumin. They should also lay in an individualized approach based on a comprehensive analysis of differences in gut microbiota between individuals and their exact curcumin intake, taking into account their genetic and epigenetic predispositions.

\section{Conflicts of Interest}

The author declares that there are no conflicts of interest.

\section{References}

[1] H. Rahmani, M. A. Alsahli, S. M. Aly, M. A. Khan, and Y. H. Aldebasi, "Role of curcumin in disease prevention and treatment," Advanced Biomedical Research, vol. 7, no. 1, p. 38, 2018.

[2] M. Mantzorou, E. Pavlidou, G. Vasios, E. Tsagalioti, and C. Giaginis, "Effects of curcumin consumption on human chronic diseases: a narrative review of the most recent clinical data," Phytotherapy Research, vol. 32, no. 6, pp. 957-975, 2018.

[3] A. Amalraj, A. Pius, S. Gopi, and S. Gopi, "Biological activities of curcuminoids, other biomolecules from turmeric and their derivatives-a review," Journal of Traditional and Complementary Medicine, vol. 7, no. 2, pp. 205-233, 2017.

[4] S. C. Gupta, S. Patchva, and B. B. Aggarwal, "Therapeutic roles of curcumin: lessons learned from clinical trials," AAPS Journal, vol. 15, no. 1, pp. 195-218, 2012.

[5] S. S. Ghosh, H. He, J. Wang, T. W. Gehr, and S. Ghosh, "Curcumin-mediated regulation of intestinal barrier function: the mechanism underlying its beneficial effects," Tissue Barriers, vol. 6, no. 1, article e1425085, 2018.

[6] K. Priyadarsini, "The chemistry of curcumin: from extraction to therapeutic agent," Molecules, vol. 19, no. 12, pp. 2009120112, 2014

[7] H. Ammon and M. Wahl, "Pharmacology of Curcuma longa," Planta Medica, vol. 57, no. 1, pp. 1-7, 2007.

[8] World Health Organization, "Rhizoma curcuma longa," in WHO Monographs on Selected Medicinal Plants, vol. 1, pp. 115-124, WHO, Geneva, Switzerland, 1999.

[9] Codex Alimentarius-International Food Standards, CAC/ MISC 6-2013: List of Codex Specifications for Food Additives, Codex Alimentarius, Rome, 2013.

[10] A. Niranjan, S. Singh, M. Dhiman, and S. K. Tewari, "Biochemical composition of curcuma longal," Accessions. Analytical Letters, vol. 46, no. 7, pp. 1069-1083, 2013.

[11] M. N. Sreejayan and M. N. A. Rao, "Curcuminoids as potent inhibitors of lipid peroxidation," Journal of Pharmacy and Pharmacology, vol. 46, no. 12, pp. 1013-1016, 2011.

[12] B. B. Aggarwal, C. Sundaram, N. Malani, and H. Ichikawa, "Curcumin: the Indian solid gold," in The Molecular Target and Therapeutic Uses of Curcumin in Health and Disease, B. B. Aggarwal, Y. J. Surh, and S. Shishodia, Eds., Springer, New York, NY, USA, 2007.

[13] B. B. Aggarwal, A. Kumar, and A. C. Bharti, "Anticancer potential of curcumin: preclinical and clinical studies," Anticancer Research, vol. 23, pp. 363-398, 2003.

[14] Y. J. Wang, M. H. Pan, A. L. Cheng et al., "Stability of curcumin in buffer solutions and characterization of its degradation products," Journal of Pharmaceutical and Biomedical Analysis, vol. 15, no. 12, pp. 1867-1876, 1997.

[15] Y. Panahi, M. S. Hosseini, N. Khalili, E. Naimi, M. Majeed, and A. Sahebkar, "Antioxidant and anti-inflammatory effects of curcuminoid-piperine combination in subjects with metabolic syndrome: a randomized controlled trial and an updated meta-analysis," Clinical Nutrition, vol. 34, no. 6, pp. 1101-1108, 2015.

[16] A. Niranjan and D. Prakash, "Chemical constituents and biological activities of turmeric (Curcuma longa 1.)-a review," Journal of Food Science and Technology, vol. 45, pp. 109-116, 2008.

[17] G. B. Mahady, S. L. Pendland, G. Yun, and Z. Z. Lu, "Turmeric (Curcuma longa) and curcumin inhibit the growth of Helicobacter pylori, a group 1 carcinogen," Anticancer Research, vol. 22, pp. 4179-4181, 2002.

[18] R. C. Reddy, P. G. Vatsala, V. G. Keshamouni, G. Padmanaban, and P. N. Rangarajan, "Curcumin for malaria therapy," Biochemical and Biophysical Research Communications, vol. 326, no. 2, pp. 472-474, 2005.

[19] B. Joe, M. Vijaykumar, and B. R. Lokesh, "Biological properties of curcumin-cellular and molecular mechanisms of action," Critical Reviews in Food Science and Nutrition, vol. 44, no. 2, pp. 97-111, 2004.

[20] B. B. Aggarwal, C. Sundaram, N. Malani, and H. Ichikawa, "Curcumin: the Indian solid gold," Advances in Experimental Medicine and Biology, vol. 595, pp. 1-75, 2007. 
[21] G. G. Yue, B. C. Chan, P. M. Hon et al., "Evaluation of in vitro anti-proliferative and immunomodulatory activities of compounds isolated from Curcuma longa," Food and Chemical Toxicology, vol. 48, no. 8-9, pp. 2011-2020, 2010.

[22] National Cancer Institute, "Clinical development plan: Curcumin," Journal of Cellular Biochemistry, vol. 26, no. 26, pp. 72-85, 1996.

[23] C. D. Lao, M. T. Ruffin, D. Normolle et al., "Dose escalation of a curcuminoid formulation," BMC Complementary and Alternative Medicine, vol. 6, no. 1, 2006.

[24] V. P. Paulucci, R. O. Couto, C. C. C. Teixeira, and L. A. P. Freitas, "Optimization of the extraction of curcumin from Curcuma longa rhizomes," Revista Brasileira de Farmacognosia, vol. 23, no. 1, pp. 94-100, 2013.

[25] K. J. Lee, H. J. Yang, S. W. Jeong, and J. Y. Ma, "Solid-phase extraction of curcuminoid from turmeric using physical process method," Korean Journal of Pharmacognosy, vol. 43, pp. 250-256, 2012.

[26] M. Li, M. O. Ngadi, and Y. Ma, "Optimization of pulsed ultrasonic and microwave-assisted extraction for curcuminoids by response surface methodology and kinetic study," Food Chemistry, vol. 165, pp. 29-34, 2014.

[27] A. L. Chassagnez-Mendez, N. C. F. Correa, L. F. Franca, N. T. Machado, and M. E. Araujo, "Mass transfer model applied to the supercritical extraction with $\mathrm{CO} 2$ of curcumins from turmeric rhizomes," Brazilian Journal of Chemical Engineering, vol. 17, no. 3, pp. 315-322, 2000.

[28] K. Patel, G. Krishna, E. Sokoloski, and Y. Ito, "Preparative separation of curcuminoids from crude curcumin and turmeric powder by $\mathrm{pH}$-zone-refining counter current chromatography," Journal of Liquid Chromatography and Related Technologies, vol. 23, no. 14, pp. 2209-2218, 2000.

[29] P. Anand, A. B. Kunnumakkara, R. A. Newman, and B. B. Aggarwal, "Bioavailability of curcumin: problems and promises," Molecular Pharmaceutics, vol. 4, pp. 807-818, 2007.

[30] A. Shehzad, F. Wahid, and Y. S. Lee, "Curcumin in cancer chemoprevention: molecular targets, pharmacokinetics, bioavailability, and clinical trials," Archiv der Pharmazie, vol. 343, no. 9, pp. 489-499, 2010.

[31] M. H. Pan, T. M. Huang, and J. K. Lin, "Biotransformation of curcumin through reduction and glucuronidation in mice," Drug Metabolism and Disposition, vol. 27, pp. 486-494, 1999.

[32] C. R. Ireson, D. J. Jones, S. Orr et al., "Metabolism of the cancer chemopreventive agent curcumin in human and rat intestine," Cancer Epidemiology, Biomarkers and Prevention, vol. 11, pp. 105-111, 2002.

[33] I. Sekirov, S. L. Russell, L. C. Antunes et al., "Gut microbiota in health and disease," Physiological Reviews, vol. 90, no. 3, pp. 859-904, 2010.

[34] J. Qin, R. Li, J. Raes et al., "A human gut microbial gene catalogue established by metagenomic sequencing," Nature, vol. 464, no. 7285, pp. 59-65, 2010.

[35] C. C. Booijink, S. El-Aidy, M. Rajilić-Stojanović et al., "High temporal and inter-individual variation detected in the human ileal microbiota," Environmental Microbiology, vol. 12, no. 12, pp. 3213-3227, 2010.

[36] E. G. Zoetendal, J. Raes, B. van den Bogert et al., "The human small intestinal microbiota is driven by rapid uptake and conversion of simple carbohydrates," ISME Journal, vol. 6, no. 7, pp. 1415-1426, 2012.
[37] M. H. Fraher, P. W. O’Toole, and E. M. M. Quigley, "Techniques used to characterize the gut microbiota: a guide for the clinician," Nature Reviews Gastroenterology and Hepatology, vol. 9, no. 6, pp. 312-322, 2012.

[38] J. Peterson, S. Garges, M. Giovanni et al., "The NIH human microbiome Project," Genome Research, vol. 19, no. 12, pp. 2317-2323, 2009.

[39] A. S. Neish, "Mucosal immunity and the microbiome," Annals of the American Thoracic Society, vol. 11, no. 1, pp. S28-S32, 2014.

[40] A. Trompette, E. S. Gollwitzer, K. Yadava et al., "Gut microbiota metabolism of dietary fiber influences allergic airway disease and hematopoiesis," Nature Medicine, vol. 20, no. 2, pp. 159-166, 2014.

[41] S. Grenham, G. Clarke, J. Cryan, and T. G. Dinan, "Braingut-Microbe communication in health and disease," Frontiers in Physiology, vol. 2, p. 94, 2011.

[42] P. Forsythe, N. Sudo, T. Dinan, V. H. Taylor, and J. Bienenstock, "Mood and gut feelings," Brain, Behavior, and Immunity, vol. 24, no. 1, pp. 9-16, 2010.

[43] J. M. Evans, L. S. Morris, and J. R. Marchesi, "The gut microbiome: the role of a virtual organ in the endocrinology of the host," Journal of Endocrinology, vol. 218, no. 3, pp. R37-R47, 2013.

[44] P. Forsythe and W. A. Kunze, "Voices from within: gut microbes and the CNS," Cellular and Molecular Life Sciences, vol. 70, no. 1, pp. 55-69, 2013.

[45] T. Tanoue, Y. Umesaki, and K. Honda, "Immune responses to gut microbiota-commensals and pathogens," Gut Microbes, vol. 1, no. 4, pp. 224-33, 2010.

[46] S. Carding, K. Verbeke, D. T. Vipond, B. M. Corfe, and L. J. Owen, "Dysbiosis of the gut microbiota in disease," Microbial Ecology in Health and Disease, vol. 26, 2015.

[47] J. L. Dunne, E. W. Triplett, D. Gevers et al., "The intestinal microbiome in type 1 diabetes," Clinical and Experimental Immunology, vol. 177, no. 1, pp. 30-37, 2014.

[48] C. J. Rogers, K. S. Prabhu, and M. Vijay-Kumar, "The microbiome and obesity: an established risk for certain types of cancer," Cancer Journal, vol. 20, no. 3, pp. 176-180, 2014.

[49] R. Francescone, V. Hou, and S. I. Grivennikov, "Microbiome, inflammation, and cancer," Cancer Journal, vol. 20, no. 3, pp. 181-189, 2014.

[50] C. McKenzie, J. Tan, L. Macia, and C. R. Mackay, "The nutrition-gut microbiome: physiology axis and allergic diseases," Immunological Reviews, vol. 278, no. 1, pp. 277295, 2017.

[51] L. Wen, R. E. Ley, P. Y. Volchkov et al., "Innate immunity and intestinal microbiota in the development of Type 1 diabetes," Nature, vol. 455, no. 7216, pp. 1109-1113, 2008.

[52] J. M. Brenchley and D. C. Douek, "Microbial translocation across the GI tract," Annual Review of Immunology, vol. 30, no. 1, pp. 149-173, 2012.

[53] Z. Ling, X. Liu, X. Jia et al., "Impacts of infection with different toxigenic Clostridium difficile strains on faecal microbiota in children," Scientific Reports, vol. 4, no. 1, p. $7485,2014$.

[54] Z. Hu, Y. Zhang, Z. Li et al., "Effect of Helicobacter pylori infection on chronic periodontitis by the change of microecology and inflammation," Oncotarget, vol. 7, no. 41, pp. 66700-66712, 2016.

[55] Z. Ling, X. Liu, Y. Cheng et al., "Decreased diversity of the oral microbiota of patients with hepatitis B virus-induced chronic liver disease: a pilot report," Scientific Reports, vol. 5, no. 1, 2015. 
[56] S. Gu, Y. Chen, X. Zhang et al., "Identification of key taxa that favor intestinal colonization of Clostridium difficile in an adult Chinese population," Microbes Infection, vol. 18, no. 1, pp. 30-38, 2016.

[57] M. Xu, B. Wang, Y. Fu et al., "Changes of fecal Bifidobacterium species in adult patients with hepatitis B virusinduced chronic liver disease," Microbial Ecology, vol. 63, no. 2, pp. 304-313, 2012.

[58] E. Le Chatelier, T. Nielsen, J. Qin et al., "Meta HIT Consortium Richness of human gut microbiome correlates with metabolic markers," Nature, vol. 500, no. 7464, pp. 541-546, 2013.

[59] J. L. Sonnenburg and F. Bäckhed, "Diet-microbiota interactions as moderators of human metabolism," Nature, vol. 535, no. 7610, pp. 56-64, 2016.

[60] F. Bäckhed, H. Ding, T. Wang et al., "The gut microbiota as an environmental factor that regulates fat storage," Proceedings of the National Academy of Sciences, vol. 101, no. 44, pp. 15718-15723, 2004.

[61] P. J. Turnbaugh, R. E. Ley, M. A. Mahowald, V. Magrini, E. R. Mardis, and J. I. Gordon, "An obesity-associated gut microbiome with increased capacity for energy harvest," Nature, vol. 444, no. 7122, pp. 1027-1031, 2006.

[62] R. J. Perry, L. Peng, N. A. Barry et al., "Acetate mediates a microbiome-brain- $\beta$-cell axis to promote metabolic syndrome," Nature, vol. 534, no. 7606, pp. 213-217, 2016.

[63] B. C. Y. Wong, S. K. Lam, W. M. Wong et al., "Helicobacter pylori eradication to prevent gastric cancer in a high-risk region of China: a randomized controlled trial," JAMA, vol. 291, no. 2, pp. 187-94, 2004.

[64] K. Lertpiriyapong, M. T. Whary, S. Muthupalani et al., "Gastric colonisation with a restricted commensal microbiota replicates the promotion of neoplastic lesions by diverse intestinal microbiota in the Helicobacter pylori INSGAS mouse model of gastric carcinogenesis," Gut, vol. 63, no. 1, pp. 54-63, 2014.

[65] N. Sanapareddy, R. M. Legge, B. Jovov et al., "Increased rectal microbial richness is associated with the presence of colorectal adenomas in humans," ISME Journal, vol. 6, no. 10, pp. 1858-68, 2012.

[66] T. O. Keku, A. N. McCoy, and A. M. Azcarate-Peril, "Fusobacterium sand colorectal cancer: cause or consequence?," Trends in Microbiology, vol. 21, no. 10, pp. 506508, 2013.

[67] Q. Feng, S. Liang, H. Jia et al., "Gut microbiome development along the colorectal adenoma-carcinoma sequence," Nature Communications, vol. 6, no. 1, p. 6528, 2015.

[68] V. Sharma, V. S. Chauhan, G. Nath, A. Kumar, and V. K. Shukla, "Role of bile bacteria in gallbladder carcinoma," Hepatogastroenterology, vol. 54, no. 78, pp. 1622-5, 2007.

[69] J. M. Walboomers, M. V. Jacobs, M. M. Manos et al., "Human papillomavirus is a necessary cause of invasive cervical cancer worldwide," Journal of Pathology, vol. 189, no. 1, pp. 12-9, 1999.

[70] N. Iida, A. Dzutsev, C. A. Stewart et al., "Commensal bacteria control cancer response to therapy by modulating the tumor microenvironment," Science, vol. 342, no. 6161, pp. 967-970, 2013.

[71] A. Lerner, R. Aminov, and T. Matthias, "Dysbiosis may trigger autoimmune diseases via inappropriate posttranslational modification of host proteins," Frontiers in Microbiology, vol. 7, p. 84, 2016.
[72] $\mathrm{H}$. J. Wu and $\mathrm{E} . \mathrm{Wu}$, "The role of gut microbiota in immune homeostasis and autoimmunity," Gut Microbes, vol. 3, no. 1, pp. 4-14, 2012.

[73] A. Lerner and T. Matthias, "Rheumatoid arthritis-celiac disease relationship: joints get that gut feeling," Autoimmunity Reviews, vol. 14, no. 11, pp. 1038-47, 2015.

[74] A. Paun and J. S. Danska, "Immuno-ecology: how the microbiome regulates tolerance and autoimmunity," Current Opinion in Immunology, vol. 37, pp. 34-9, 2015.

[75] J. L. Benjamin, C. R. H. Hedin, A. Koutsoumpas et al., "Smokers with active Crohn's disease have a clinically relevant dysbiosis of the gastrointestinal microbiota," Inflammatory Bowel Diseases, vol. 18, no. 6, pp. 1092-1100, 2012.

[76] F. Lutgendorff, L. M. A. Akkermans, and J. D. Soderholm, "The role of microbiota and probiotics in stress-induced gastrointestinal damage," Current Molecular Medicine, vol. 8, no. 4 , pp. 282-298, 2008.

[77] E. A. Magee, C. J. Richardson, R. Hughes, and J. H. Cummings, "Contribution of dietary protein to sulfide production in the large intestine: an in vitro and a controlled feeding study in humans," American Journal of Clinical Nutrition, vol. 72, no. 6, pp. 1488-1494, 2000.

[78] G. Glenn and M. Roberfroid, "Dietary modulation of the human colonic microbiota: introducing the concept of prebiotics," Journal of Nutrition, vol. 125, no. 6, pp. 14011412, 1995.

[79] H. Daniel, A. M. Gholami, D. Berry et al., "High-fat diet alters gut microbiota physiology in mice," ISME Journal, vol. 8, no. 2, pp. 295-308, 2014.

[80] G. D. Wu, J. Chen, C. Hoffmann et al., "Linking long-term dietary patterns with gut microbial enterotypes," Science, vol. 334, no. 6052, pp. 105-108, 2011.

[81] J. Purushe, D. E. Fouts, M. Morrison et al., "Comparative genome analysis of Prevotella ruminicola and Prevotella bryantii: insights into their environmental niche," Microbial Ecology, vol. 60, no. 4, pp. 721-729, 2010.

[82] D. N. Frank, A. L. S. Amand, R. A. Feldman, E. C. Boedeker, N. Harpaz, and N. R. Pace, "Molecular-phylogenetic characterization of microbial community imbalances in human inflammatory bowel diseases," Proceedings of the National Academy of Sciences, vol. 104, no. 34, pp. 13780 13785, 2007.

[83] F. De Filippis, N. Pellegrini, L. Vannini et al., "High-level adherence to a Mediterranean diet beneficially impacts the gut microbiota and associated metabolome," Gut, vol. 65, no. 11, pp. 1812-1821, 2016.

[84] B. B. Matijasic, T. Obermajer, L. Lipoglavsek, I. Grabnar, G. Avgustin, and I. Rogelj, "Association of dietary type with fecal microbiota in vegetarians and omnivores in Slovenia," European Journal of Nutrition, vol. 53, no. 4, pp. 1051-1064, 2014.

[85] L. Shen and H. F. Ji, "Intestinal microbiota and metabolic diseases: pharmacological Implications," Trends in Pharmacological Sciences, vol. 37, no. 3, pp. 169-171, 2016.

[86] L. Shen, L. Liu, and H. F. Ji, "Regulative effects of curcumin spice administration on gut microbiota and its pharmacological implications," Food and Nutrition Research, vol. 61, no. 1, article 1361780, 2017.

[87] A. K. Greiner, R. V. L. Papineni, and S. Umar, "Chemoprevention in gastrointestinal physiology and disease, Natural products and microbiome," American Journal of Physiology-Gastrointestinal and Liver Physiology, vol. 307, no. 1, pp. G1-G15, 2014. 
[88] G. P. Schincaglia, B. Y. Hong, A. Rosania et al., "Clinical, immune, and microbiome traits of gingivitis and periimplant mucositis," Journal of Dental Research, vol. 96, no. 1, pp. 47-55, 2017.

[89] R. M. McFadden, C. B. Larmonier, K. W. Shehab et al., "The role of curcumin in modulating colonic microbiota during colitis and colon cancer prevention," Inflammatory Bowel Diseases, vol. 21, no. 11, pp. 2483-94, 2015.

[90] M. Borges-Canha, J. P. Portela-Cidade, M. Dinis-Ribeiro, A. F. Leite-Moreira, and P. Pimentel-Nunes, "Role of colonic microbiota in colorectal carcinogenesis: a systematic review," Revista Española de Enfermedades Digestivas, vol. 107, pp. 659-71, 2015.

[91] R. Rashmi, T. R. Santhosh Kumar, and D. Karunagaran, "Human colon cancer cells differ in their sensitivity to curcumin-induced apoptosis and heat shock protects them by inhibiting the release of apoptosis-inducing factor and caspases," FEBS Letters, vol. 538, no. 1-3, pp. 19-24, 2003.

[92] S. Lev-Ari, L. Strier, D. Kazanov et al., "Celecoxib and curcumin synergistically inhibit the growth of colorectal cancer cells," Clinical Cancer Research, vol. 11, no. 18, pp. 6738-6744, 2005.

[93] K. Wang, T. Zhang, L. Liu et al., "Novel micelle formulation of curcumin for enhancing antitumor activity and inhibiting colorectal cancer stem cells," International Journal of Nanomedicine, vol. 7, pp. 4487-97, 2012.

[94] A. L. Cheng, C. H. Hsu, J. K. Lin et al., "Phase I clinical trial of curcumin, a chemopreventive agent, in patients with high risk or pre-malignant lesions," Anticancer Research, vol. 21, pp. 2895-2900, 2001.

[95] R. A. Sharma, S. A. Euden, S. L. Platton et al., "Phase I clinical trial of oral curcumin: biomarkers of systemic activity and compliance," Clinical Cancer Research, vol. 10, no. 20, pp. 6847-6854, 2004.

[96] J. J. Johnson and H. Mukhtar, "Curcumin for chemoprevention of colon cancer," Cancer Letters, vol. 255, no. 2, pp. 170-181, 2007.

[97] M. Ohno, A. Nishida, Y. Sugitani et al., "Nanoparticle curcumin ameliorates experimental colitis via modulation of gut microbiota and induction of regulatory T cells," PLoS ONE, vol. 12, no. 10, Article ID e0185999, 2017.

[98] P. R. Holt, S. Katz, and R. Kirshoff, "Curcumin therapy in inflammatory bowel disease: a pilot study," Digestive Diseases and Sciences, vol. 50, no. 11, pp. 2191-2193, 2005.

[99] A. Lang, N. Salomon, and J. C. Wu, "Curcumin in combination with mesalamine induces remission in patients with mild-to- moderate ulcerative colitis in a randomized controlled trial," Clinical Gastroenterology and Hepatology, vol. 13, no. 8, pp. 1444-9, 2015.

[100] A. Parian and B. N. Limketkai, "Dietary supplement therapies for inflammatory bowel disease: crohn's disease and ulcerative colitis," Current Pharmaceutical Design, vol. 22, no. 2, pp. 180-188, 2016.

[101] M. H. Farzaei, R. Bahramsoltani, A. H. Abdolghaffari, H. R. Sodagari, S. A. Esfahani, and N. Rezaei, "A mechanistic review on plant-derived natural compounds as dietary supplements for prevention of inflammatory bowel disease," Expert Review of Gastroenterology and Hepatology, vol. 10, no. 6, pp. 745-758, 2016.

[102] R. Olszanecki, J. Jawien, M. Gajda et al., "Effect of curcumin on atherosclerosis in ApoE/LDLR-double knockout mice," Journal of Physiology and Pharmacology, vol. 56, no. 4, pp. 627-635, 2005.
[103] W. Feng, H. Wang, P. Zhang et al., "Modulation of gut microbiota contributes to curcumin-mediate attenuation of hepatic steatosis in rats," Biochimica Biophysica Acta, vol. 1861, no. 7, pp. 1801-12, 2017.

[104] J. Wang, S. S. Ghosh, and S. Ghosh, "Curcumin improves intestinal barrier function: modulation of intracellular signaling, and organization of tight junctions," American Journal of Physiology Cell Physiology, vol. 312, no. 4, pp. C438-C445, 2017.

[105] S. Bereswill, M. Munoz, A. Fischer et al., "Anti-inflammatory effects of resveratrol, curcumin and simvastatin in acute small intestinal inflammation," PLoS One, vol. 5, no. 12, Article ID e15099, 2010.

[106] K. B. Soni and R. Kuttan, "Effect of oral curcumin administration on serum peroxides and cholesterol levels in human volunteers," Indian Journal of Physiology and Pharmacology, vol. 36, no. 4, pp. 273-275, 1992.

[107] A. Shimouchi, K. Nose, M. Takaoka, H. Hayashi, and T. Kondo, "Effect of dietary turmeric on breath hydrogen," Digestive Diseases and Sciences, vol. 54, no. 8, pp. 1725-9, 2009.

[108] Z. Zhang, Y. Chen, L. Xiang, Z. Wang, G. G. Xiao, and J. Hu, "Article effect of curcumin on the diversity of gut microbiota in ovariectomized rats," Nutrients, vol. 9, no. 10, p. 1146, 2017.

[109] N. Dey, V. E. Wagner, L. V. Blanton et al., "Regulators of gut motility revealed by a gnotobiotic model of diet-microbiome interactions related to travel," Cell, vol. 163, no. 1, pp. 95-107, 2015.

[110] C. T. Peterson, A. R. Vaughn, V. Sharma et al., "Effects of turmeric and curcumin dietary supplementation on human gut microbiota: a double-blind, randomized, placebocontrolled pilot study," Journal of Evidence-Based Integrative Medicine, vol. 23, pp. 1-8, 2018.

[111] A. S. Strimpakos and R. A. Sharma, "Curcumin: preventive and therapeutic properties in laboratory studies and clinical trials," Antioxidants and Redox Signaling, vol. 10, no. 3, pp. 511-545, 2008.

[112] M. Gotteland, M. Andrews, M. Toledo et al., "Modulation of Helicobacter pylori colonization with cranberry juice and Lactobacillus johnsonii La1 in children," Nutrition, vol. 24, no. 5, pp. 421-426, 2008.

[113] L. Makras, V. Triantafyllou, D. Fayol-Messaoudi et al., "Kinetic analysis of the antibacterial activity of probiotic lactobacilli towards Salmonella enterica serovar typhimurium reveals a role for lactic acid and other inhibitory compounds," Research in Microbiology, vol. 157, no. 3, pp. 241-247, 2006.

[114] S. Burapan, M. Kim, and J. Han, "Curcuminoid demethylation as an alternative metabolism by human intestinal microbiota," Journal of Agricultural and Food Chemistry, vol. 65, no. 16, pp. 3305-3310, 2017.

[115] S. Tan, L. Calani, L. Bresciani et al., "The degradation of curcuminoids in a human faecal fermentation model," International Journal of Food Sciences and Nutrition, vol. 66, no. 7, pp. 790-796, 2015.

[116] A. Hassaninasab, Y. Hashimoto, K. Tomita-Yokotani, and M. Kobayashi, "Discovery of the curcumin metabolic pathway involving a unique enzyme in an intestinal microorganism," Proceedings of the National Academy of Sciences, vol. 108, no. 16, pp. 6615-6620, 2011.

[117] W. Herath, D. Ferreira, and I. A. Khan, "Microbial metabolism. Part 7: curcumin," Natural Product Research, vol. 21, no. 5, pp. 444-450, 2007. 
[118] Z. Li, Y. Sun, M. Song, F. Li, and H. Xiao, "Gut microbiota dictate metabolic Fate of Curcumin in the colon," Nutrition, vol. 31, no. 1, 2017.

[119] A. Asai and T. Miyazawa, "Occurrence of orally administered curcuminoid as glucuronide and glucuronide/sulfate conjugates in rat plasma," Life Sciences, vol. 67, no. 23, pp. 2785-2793, 2010.

[120] Y. Lou, J. Zheng, H. Hu, J. Lee, and S. Zeng, "Application of ultra-performance liquid chromatography coupled with quadrupole time-of-flight mass spectrometry to identify curcumin metabolites produced by human intestinal bacteria," Journal of Chromatography B, vol. 985, pp. 38-47, 2015.

[121] M. Metzler, E. Pfeiffer, S. I. Schulz, and J. S. Dempe, "Curcumin uptake and metabolism," Biofactors, vol. 39, no. 1, pp. 14-20, 2013.

[122] Y. Sugiyama, S. Kawakishi, and T. Osawa, "Involvement of the beta-diketone moiety in the antioxidative mechanism of tetrahydrocurcumin," Biochemical Pharmacology, vol. 52, no. 4, pp. 519-525, 1996.

[123] J. C. Wu, M. L. Tsai, C. S. Lai, Y. J. Wang, C. T. Ho, and M. H. Pan, "Chemopreventative effects of tetrahydrocurcumin on human diseases," Food and Function, vol. 5, no. 1, pp. 12-7, 2014.

[124] F. Zhao, Y. Gong, Y. Hu et al., "Curcumin and its major metabolites inhibit the inflammatory response induced by lipopolysaccharide: translocation of nuclear factor- $\kappa \mathrm{B}$ as potential target," Molecular Medicine Reports, vol. 11, no. 4, pp. 3087-3093, 2015.

[125] C. H. An, Z. Z. Sun, L. Shen, and H. F. Ji, "Biotransformation of food spice curcumin by gut bacterium Bacillus megaterium DCMB-002 and its pharmacological implications," Food and Nutrition Research, vol. 61, no. 1, article 1412814, 2017. 


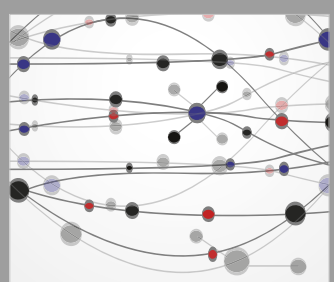

The Scientific World Journal
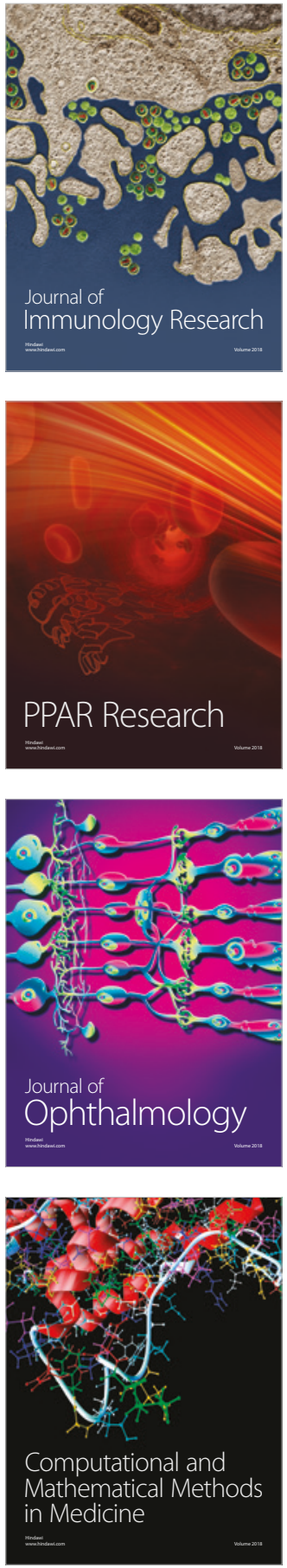

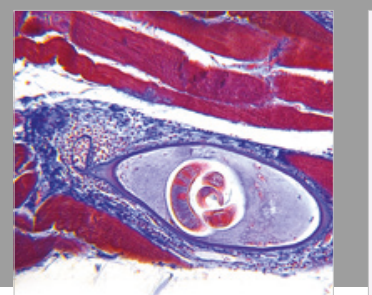

Gastroenterology Research and Practice

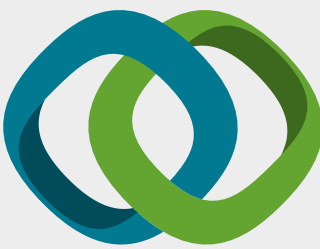

\section{Hindawi}

Submit your manuscripts at

www.hindawi.com
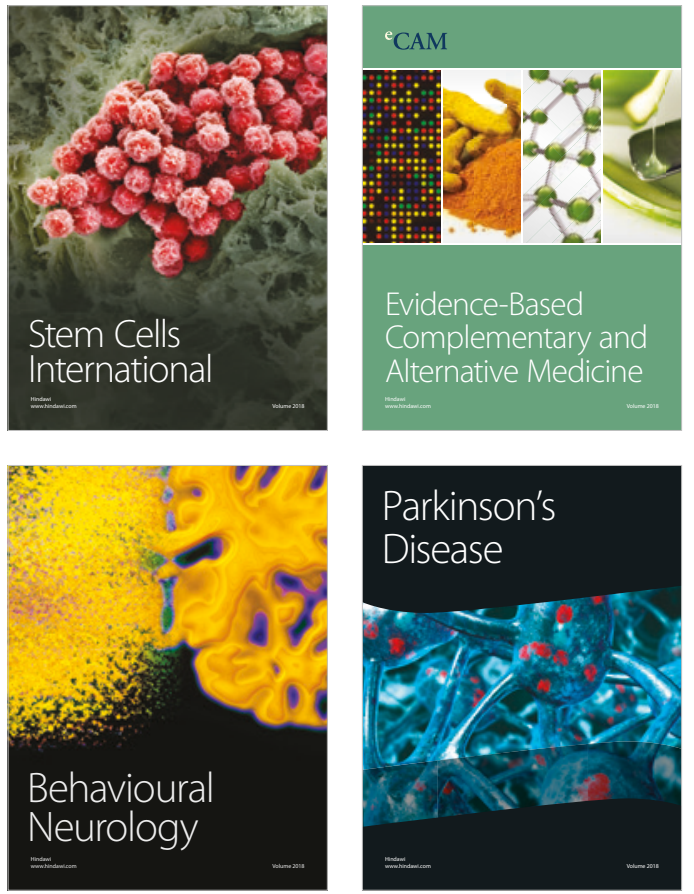

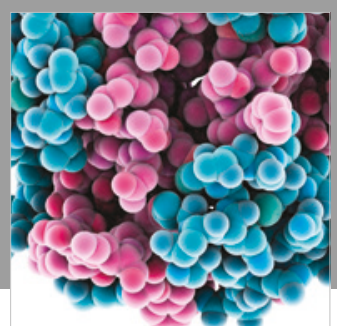

ournal of

Diabetes Research

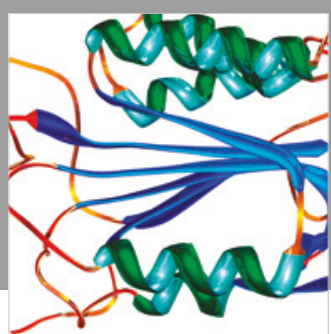

Disease Markers
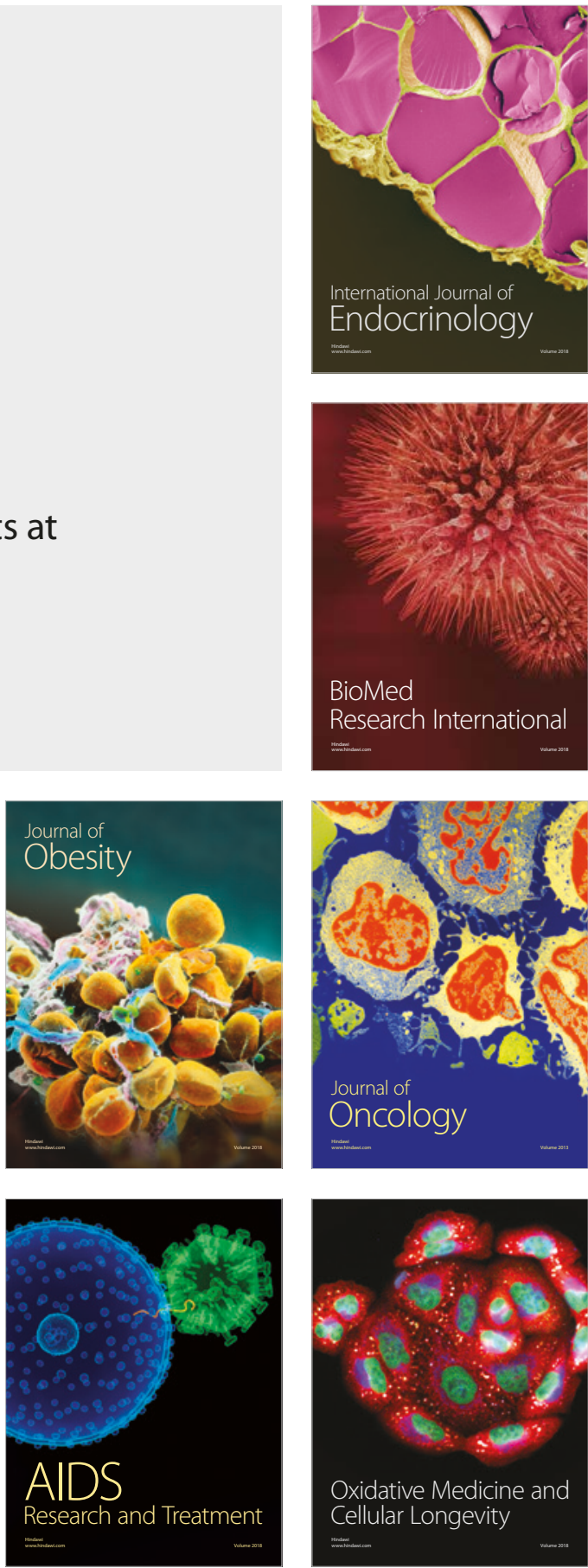